\title{
O Goodwill gerado pelo Passivo
}

\author{
Resumo \\ Objetivo: $\mathrm{O}$ objetivo deste estudo está relacionado à figura do \\ Goodwill originado do Passivo de uma empresa, ou seja, não é a \\ do Goodwill normalmente constituído pelos Ativos Intangíveis \\ capazes de produzir uma rentabilidade anormal e que fazem \\ com que o valor da entidade como um todo, em funcionamento, \\ seja maior do que a soma algébrica dos valores justos de seus \\ elementos patrimoniais. Trata-se de uma visão que se pode \\ entender como novidade para muitos, ou seja, a do Goodwill \\ originado do Passivo e, não, dos Ativos de uma empresa. \\ Existem empresas que sequer conseguem remunerar o risco que \\ seus Ativos carregam, mas podem apresentar Goodwill devido à \\ forma com que suas atividades são financiadas. \\ Método: Como ensaio, são apresentados conceitos básicos e de \\ formulação, normalmente utilizados em avaliações de empresas. \\ $\mathrm{Na}$ sequência, são apresentadas simulações que demonstram, de \\ forma objetiva, o verdadeiro sentido técnico da formulação. \\ Resultados: Sabendo-se que determinadas agências estatais \\ de desenvolvimento e o próprio BNDES acabam financiando \\ determinadas atividades com taxas de juros generosas, este \\ estudo apresenta ainda um caso real de existência de Goodwill \\ originado do Passivo de uma empresa brasileira. \\ Contribuições: Este trabalho tem como uma de suas principais \\ contribuições a exposição de um tema que é praticamente \\ desconhecido no mundo acadêmico, totalmente desconsiderado \\ pelas normas e legislações contábeis, mas presente no mundo \\ dos analistas e investidores mais bem preparados, e o faz pela \\ não disseminação desse conceito, com apresentação e redação \\ acessíveis a todos os níveis de leitores. \\ Palavras-chave: Goodwill; Goodwill Passivo; Valor Econômico \\ do PL; Unidade Consumidora de Caixa; Taxas de Juros \\ Generosas.
}

\section{Eliseu Martins}

Professor Emérito da Universidade de São Paulo (USP), FEA-SP e FEA-RP. Contato: Av. Bandeirantes, 3900, FEARP. Monte Alegre. Ribeirão Preto (SP). CEP: 14040-905.

E-mail: prof.eliseu.martins@gmail.com

\section{Ariovaldo dos Santos}

Professor Titular da Faculdade de Economia, Administração e Contabilidade da Universidade de São Paulo (FEA-USP). Contato: Av. Prof. Luciano Gualberto, 908, FEA 3. Cidade Universitária. São Paulo (SP). CEP: 05508-900.

E-mail: arisanto@usp.br 


\section{Introdução}

Toda a vez que falamos de ágio por expectativa de rentabilidade futura, ou Goodwill (até na Lei brasileira - Lei n. ${ }^{\circ}$ 12.973/2013), lembramo-nos de Ativo. Nos livros de Teoria da Contabilidade, nos livros didáticos, nos artigos científicos, nos trabalhos acadêmicos e profissionais em geral isso também ocorre. Nas normas contábeis idem, como é o caso dos Pronunciamentos Técnicos CPC 04 (R1) - Ativo Intangível e CPC 15 (R1) - Combinação de Negócios.

Mas esse vínculo ao Ativo não é só porque, quando contabilizável, fica esse ágio no Ativo da Entidade Adquirente que por ele tenha pago, mas também porque é sempre referenciado a um Ativo da Entidade Adquirida representado por sua capacidade de geração de lucro anormal. Na verdade, só é Ativo na adquirente porque é considerado como um Ativo da Adquirida que não está contabilizado nesta e, consequentemente, fora do alcance da Equivalência Patrimonial pela primeira.

Mas todas as nossas considerações presentes nesse estudo não dizem respeito ao Goodwill registrado em uma adquirente e, sim, na entidade que realmente possui a capacidade de geração de lucros anormais, quer seja ela adquirida por alguém ou não, ou seja, falamos da entidade genuinamente possuidora desse intangível.

De qualquer maneira, vamos utilizar o conceito formal hoje da Contabilidade que, simplificadamente, determina que ele seja mensurado pelo que o valor justo da entidade exceder o valor justo da soma algébrica dos seus Ativos e Passivos identificáveis individualmente tomados (Pronunciamento Técnico CPC 15 (R1), itens 18 e 32). Assim, teremos como definição: o Goodwill corresponde à diferença entre o valor justo da entidade como um todo e o valor justo algébrico de seus Ativos e seus Passivos identificáveis individuais.

Ou seja, estaremos aqui trabalhando com o que Edwards e Bell (1961) denominaram de Goodwill Subjetivo, dependente de um critério de mensuração aceito para determinação do valor da empresa como um todo, em marcha, diferente do que pode ser o Goodwill Objetivo definido pelo valor de uma transação em particular. $\mathrm{O}$ valor justo da entidade em marcha trataremos como sendo o valor econômico fundamentado no valor presente dos fluxos de caixa futuros (sem aqui detalhar, por enquanto, se fluxo de dividendos, fluxo de caixa para a firma, para os acionistas, etc.).

As normas e a literatura sempre atribuíram a figura do Goodwill à existência de atributos de natureza intangível não separáveis e negociáveis individualmente, tais como reputação, imagem, qualidade de produtos, força de trabalho, market share, proficiência em pesquisas, posicionamento estratégico, etc., que sejam responsáveis pela capacidade da empresa de produzir lucros (e fluxos de caixa, consequentemente) acima do risco normal do negócio. Daí toda essa caracterização volta a atenção a esses atributos, genuínos "Ativos" do ponto de vista econômico, apesar de não passíveis de reconhecimento contábil.

Não é intuito aqui ir além dessas considerações conceituais básicas, mesmo porque vamos trabalhar com hipóteses extremamente simplificadas que permitem isso. $O$ fundamental é ficarmos com a ideia do Goodwill como o mais intangível dos intangíveis e que representa a soma desses fatores formadores da anormalidade da rentabilidade da entidade. Sabidamente, além da dificuldade de determinação dos valores dos fluxos de caixa esperados, há toda aquela relativa ao que deveria ser o lucro normal de uma empresa, considerando os riscos envolvidos e o fator tempo. E como não é também esse o objetivo aqui, simplesmente vamos dá-los como conhecidos para fins de desenvolvimento do pretendido.

\section{O Objetivo deste Trabalho}

Nosso objetivo aqui é, para talvez muitos, levar uma novidade, e para o que acreditamos sejam muito poucos, lembrar que o Goodwill nem sempre está entre os "Ativos" econômicos da entidade, como os elencados logo atrás e que, às vezes, ou na verdade, quase sempre, parte dele está nos seus Passivos. Há muitas empresas que possuem Goodwill, mas que podem não ter, na verdade, quaisquer Ativos capazes de remunerar o risco que carregam, sendo esse Goodwill derivado dos Passivos que financiam suas atividades. 
Queremos expandir a ideia de que a literatura e as normas de contabilidade e os avaliadores de patrimônios empresariais em geral, sempre com alguma exceção, vêm desprezando essa característica muito mais presente do que se imagina: parte do Goodwill de uma empresa deriva da forma como ela é financiada e, não, da capacidade de geração de lucros e caixa de seus Ativos, tomados aqui os tangíveis e os intangíveis. Essa falha está totalmente presente também nas normas de contabilidade, inclusive as internacionais, haja vista que todo o teste de Recuperabilidade de Ativos em uma investidora, no que diz respeito ao possível impairment do Goodwill, está centrado nesse pensamento.

Dos itens 65 ao 90, no Pronunciamento Técnico CPC 01 (R1) - Redução ao Valor Recuperável dos Ativos - o que se discute é, basicamente o seguinte: se um determinado Ativo em particular não for o gerador da rentabilidade anormal, procura-se qual a "unidade geradora de caixa" que o seja. Assim, está presente a ideia de que o Goodwill está sempre relacionado à figura de um Ativo ou de um conjunto de Ativos que, no seu todo, possa estar apresentando essa geração anormal de lucros e caixa. Aqueles fatores intangíveis que normalmente são dados como suportadores do Goodwill deveriam, pela norma, estar sempre vinculados a um Ativo em particular ou a um determinado conjunto de Ativos denominado de "unidade geradora de caixa".

Em lugar algum aparece que a "unidade geradora de caixa" poderia ser, na verdade, uma "unidade consumidora de caixa", como é o Passivo. Esse assunto tem sido cuidado de forma extremamente parcimoniosa na literatura contábil, só que, é claro, de forma alguma passa despercebida aos sagazes investidores.

Mas temos, no Brasil, um modelo inédito para essa identificação e mensuração do quanto do Goodwill total de uma empresa deriva exclusivamente de seu Passivo. Precisamos, então, não só disseminá-lo (na verdade disseminar o conceito e o modelo) para fins acadêmicos como também profissionais, e também exportá-los para análise e eventual aceitação nos órgãos reguladores e normatizadores contábeis. Essa é a nossa grande motivação.

\section{Uma Didática Introdução ao Assunto}

\subsection{Antecedentes}

O que chama a atenção é que o mundo prático tem muito mais consciência do conceito de Goodwill no Passivo do que o acadêmico. Por exemplo, em alguns segmentos, a avaliação e a negociação de empresas gira em torno da qualidade e do volume do Passivo. Tradicionalmente, em alguns mercados, como principalmente o norte-americano, a negociação de bancos considera fortemente e, às vezes, quase que unicamente, a qualidade e a dimensão de suas contas de Passivo que representam a captação de recursos. Nos bancos comerciais mais tradicionais, o Depósito à Vista é o centro de atenção. Tanto que alguns pequenos bancos se especializam nessa captação para venda dessa carteira a outros bancos.

No Brasil esse caso específico dos Depósitos, mais tratado internacionalmente, já mereceu alguns trabalhos; veja-se a dissertação de mestrado de Martins (2002), com o sugestivo título: Contribuição à Avaliação do Goodwill: Depósitos Estáveis, um Ativo Intangível. Nela há citação de bibliografia à época, praticamente estrangeira, mas existente. Veja-se outro trabalho derivado desse: Leão e Vasconcelos (2010).

O mesmo autor, pouco depois, introduziu a generalização do Goodwill no Passivo, e que se saiba em âmbito internacional, com sua tese de doutorado Interações entre Estrutura de Capital, Valor da Empresa e Valor dos Ativos (Martins, 2005). Mais do que isso, introduziu formulação específica para dimensionamento desse Goodwill. Os conceitos básicos desse trabalho é que fundamentam este.

Fora disso, raríssimos papers cuidaram da matéria. Nunca conseguimos entender o porquê. Os principais foram Kane, Marcus e McDonald (1985), Choi (1988), Martins, Carvalho e Assaf Neto (2008), Cheng e Tzeng (2011) e Martins e Martins (2015). Na verdade, de forma direta apenas o terceiro e o quinto tratam da matéria. 


\subsection{Introduzindo Conceito e Cálculo}

Para procurar desmistificar a matéria, admitam-se algumas premissas simplificadoras e mais o seguinte.

Sejam:

- A o valor contábil de um Ativo produtor de um fluxo perpétuo de lucro e caixa (reinvestimentos iguais à depreciação, para simplificar o máximo possível);

- $\quad P$ o Passivo financeiro e $P L$ o capital próprio contábeis financiadores integrais de $A$, também perpétuos;

- $\quad x$ a taxa de retorno de $A$;

- $\quad k d$ a taxa de juros de $P$, juros pagos conforme incorridos;

- $\quad k e$ o custo do capital próprio;

- $r$ a taxa de imposto de renda sobre o lucro; e,

- L o lucro líquido, o caixa líquido produzido pela empresa e o valor dos dividendos.

Assim, sendo o Ativo, o Passivo e o lucro líquido perpétuos e, dada a hipótese anterior, esse lucro líquido é igual ao caixa líquido produzido pela empresa (porque os investimentos se igualam à depreciação), e sendo esse lucro líquido totalmente distribuído nunca acumulará caixa, e o balanço eternamente será $A=P+P L$, e o lucro líquido será eternamente:

$A \times x=$ resultado e caixa produzidos pelo Ativo antes dos impostos;

$P \times k d=$ despesas financeiras apropriadas e pagas, também antes dos impostos.

$L=(A \times x-P \times k d) \times(1-r)$

Ou, para uma visualização mais clara dos valores líquidos do imposto de renda:

Lucro operacional líquido gerado pelo Ativo $=$ Caixa operacional líquido gerado pelo Ativo $=$ $A \times x \times(1-r)$;

Despesas Financeiras líquidas do tributo $=P \times k d \times(1-r)$.

$$
L=A \times x \times(1-r)-P \times k d \times(1-r)
$$

O Valor Econômico do Patrimônio Líquido $\left(V_{P L}\right)$ será dado pelo valor presente do lucro líquido, ou seja, valor presente dos dividendos, igual ainda ao valor presente do fluxo de caixa líquido dos acionistas (condições válidas para as simplificações adotadas). Dada a perpetuidade, sendo $V_{P L}$ esse valor econômico, e lembrando o ke como o custo do capital próprio dos acionistas, tem-se:

$$
V_{P L}=\frac{L}{k e}
$$

Introduzamos agora a hipótese de que os valores justos individuais dos componentes de $A$ e de $P$ sejam exatamente iguais aos seus valores contábeis. Assim, sendo Go Goodwill, ele existirá se esse $V_{P L}$ for maior que $P L$. E vamos aqui assumir que $V_{P L}$ será sempre igual ou maior do que $P L$, para evitar complicação com a figura do ganho por compra vantajosa (jocosamente Badwill).

$$
G=V_{P L}-P L
$$


Para uma simplificação maior e visão mais clara possível, admita-se que esse Ativo $A$ seja capaz de produzir um retorno líquido do tributo exatamente igual ao custo do capital próprio. Na verdade, deveria ser dito o contrário: se o Ativo for financiado totalmente pelo Patrimônio Líquido, o custo do capital próprio deve conter exatamente o risco único que corre, que é o risco desse Ativo. Assim, nessa condição:

$$
k e=x \times(1-r)
$$

E também por simplificação, vamos admitir que esse custo do capital próprio ke não se altere mesmo na presença de Passivo dentro de certos limites. Podemos então definir que o Valor Econômico do Patrimônio Líquido, anteriormente dado por (3), fica:

$$
V_{P L}=\frac{L}{k e}=\frac{A \times x \times(1-r)}{k e}-\frac{P \times k d \times(1-r)}{k e}
$$

O primeiro termo da Equação 6 é exatamente o Valor Econômico do Ativo, $\mathrm{V}_{\mathrm{A}}$, já que ele representa o fluxo de caixa líquido produzido por esse Ativo trazido a valor presente pelo seu custo de oportunidade, dado pelo ke conforme admitido logo anteriormente. Assim, teríamos para o primeiro termo da Equação 6:

$$
V_{A}=\frac{A \times x \times(1-r)}{k e}
$$

Só que como $k e=x \times(1-r)$, conclui-se, na verdade, que:

$$
V_{A}=\frac{A \times k e}{k e}
$$

Ou seja, o Valor Econômico do Ativo neste caso é exatamente igual ao seu Valor Contábil, que também tomamos como igual ao seu Valor Justo.

$$
V A=A
$$

Se o Valor Econômico do Ativo é o seu próprio Valor Contábil e justo, isso significa que não existe Goodwill nesse Ativo dadas essas hipóteses assumidas.

Vejamos agora o segundo termo: ele representa o Valor Econômico do Passivo na visão da empresa e seus sócios, $V_{P}$, conforme Equação 10.

$$
V_{P}=\frac{P \times k d \times(1-r)}{k e}
$$

Essa última expressão significa que o Valor Econômico de uma dívida perpétua igual à despesa financeira que ele gera trazida a valor presente pelo custo do capital dos acionistas. E a não ser que $k d \times(1-r)$ também seja igual a ke (hipótese remota, mas é possível que possa ocorrer), o Valor Econômico do Passivo não será igual ao seu Valor Contábil; na hipótese de a taxa de despesa financeira, líquida do imposto de renda, ser inferior ao custo do capital próprio, que é o absolutamente normal em uma economia minimamente organizada e em uma empresa não em processo de falência, teremos que:

$$
V_{P}<P
$$


O que significa isso? Para os acionistas, o raciocínio é o seguinte: o fluxo de pagamentos desse Passivo, trazido a valor presente pelo custo do capital próprio, tem, normalmente, um valor presente inferior ao que seria esse fluxo descontado pela sua própria taxa líquida de juros (como regra, este fluxo é o próprio valor justo do Passivo).

Ora, se o Valor Econômico de um Passivo é menor do que seu Valor Contábil, e seu Valor Contábil corresponde ao seu Valor Justo (de mercado), isso significa que há um ganho para os acionistas nesse Passivo, ou seja, o Goodwill da empresa está no seu Passivo e, não, no Ativo. Valor Econômico do Ativo maior do que seu Valor Justo significa existência de Goodwill. No Passivo é o contrário: Valor Econômico do Passivo menor do que seu Valor Justo é que significa a existência de Goodwilli. Há outras formas de provar isso, mas vamos a uma simulação primeiramente para fixar melhor o conceito.

\section{Introduzindo uma Simulação}

Se substituirmos toda essa álgebra, mesmo que simplérrima, por números de uma simulação, deverá ficar mais claro ainda.

Admitamos então que a empresa $E$ possui, em milhares de reais e em percentuais anuais, o seguinte desempenho, supondo que sejam valores também tomados em perpetuidade, e investimentos periódicos iguais às depreciações:

$$
\begin{aligned}
& \text { Ativos }(A)=\mathrm{R} \$ 100.000 \times \text { Lucro Operac. Antes Impostos }(x)=15 \% \quad \mathrm{R} \$ 15.000 \\
& \text { Impostos sobre o Lucro Operacional }(r)=30 \% \quad(\underline{\mathrm{R} \$ 4.500}) \\
& \text { Lucro Operac. Líquido }(L o)=\text { Caixa Líquido das Operações }=10,5 \% \quad \mathrm{R} \$ 10.500 \\
& \text { Passivos }(P)=\mathrm{R} \$ 40.000 \times \text { Desp. Financ. Antes Impostos }(k d)=10 \% \quad(\mathrm{R} \$ 4.000) \\
& \text { Impostos recuperados }=30 \% \quad \underline{\mathrm{R} \$ 1.200} \\
& \text { Despesas Financeiras Líquidas de Impostos }=7 \% \quad(\mathrm{R} \$ 2.800) \\
& \text { Lucro Líquido }(L)=\quad \mathrm{R} \$ 7.700
\end{aligned}
$$

Patrimônio Líquido $(P L)=\mathrm{R} \$ 60.000 \rightarrow$ à Taxa de Retorno de $12,8 \%$

Admitamos agora que o custo do capital próprio $(k e)$ seja 10,5\%. Assim, o Valor Econômico da empresa será de:

$$
\begin{aligned}
& V_{P L}=\frac{L}{(k e)}, \text { conforme Equação } 3 . \\
& V_{P L}=\frac{R \$ 7.700}{10,5 \%}=R \$ 73.333
\end{aligned}
$$

Ora, se o Valor Justo dos Ativos e Passivos é igual ao seu Valor Contábil, segue que o Goodwill dessa empresa é, conforme Equação 4:

$$
G=V_{P L^{-}}-P L=R \$ 73.333-R \$ 60.000=R \$ 13.333
$$

Mas qual é a origem desse Goodwill? Qual é a unidade geradora de caixa que o produz? O Ativo como um todo? Equação 7:

Seguindo a mesma lógica já demonstrada, temos que o Valor Econômico do Ativo é dado pela 


$$
V_{A}=\frac{A \times x \times(1-r)}{k e}=\frac{R \$ 100,000 \times 15 \% \times(1-30 \%)}{10.5 \%}=R \$ 100,000
$$

Ou seja, o Valor Econômico do Ativo é exatamente igual ao seu Valor Contábil. Onde está o Goodwill que esse Ativo conteria? Que rentabilidade anormal ele produz? Visivelmente nenhum.

Por outro lado, o Passivo tem o seguinte Valor Econômico, conforme Equação 10:

$$
V_{P}=\frac{P \times k d \times(1-r)}{k e}=\frac{R \$ 40,000 \times 10 \% \times(1-30 \%)}{10.5 \%}=\mathrm{R} \$ 26,667
$$

Como o Passivo a Valores Contábil e Justo é de $\mathrm{R} \$ 40.000$, há um Ganho nesse Passivo de $\mathrm{R} \$ 13.333$, e essa é a origem do Goodwill da empresa.

Uma forma simples de provar isso é:

a) se o Ativo fosse financiado exclusivamente pelo Patrimônio Líquido, o Lucro Líquido seria igual ao Lucro Operacional Líquido (igual ao Caixa Operacional Líquido produzido pelo Ativo) e seria de $\mathrm{R} \$ 10.500$; e o Patrimônio Líquido seria de $\mathrm{R} \$ 100.000$, com os acionistas ganhando então exatamente 10,5\%, igual ao seu ke, o que significaria inexistência de Goodwill;

b) como os acionistas investiram só $\mathrm{R} \$ 60.000$, e ganharam $\mathrm{R} \$ 7.700$, obtiveram uma taxa de retorno de $12,8 \%$, que é superior ao seu custo de capital próprio de 10,5\%. Assim, há lucro anormal, gerador de Goodwill. E o único fator diferenciador entre a) e b) é a presença do Passivo. Ele é o gerador do Goodwill e, não, o Ativo da empresa.

Outra forma de comprovação é:

a) Os acionistas investiram $\mathrm{R} \$ 60.000$ e esse montante produziu, no Ativo, a taxa líquida de retorno de $10,5 \%$, ou seja, $\mathrm{R} \$ 6.300$;

b) Tomaram dinheiro emprestado de $\mathrm{R} \$ 40.000$ que, aplicados no Ativo, produziram:

i Retorno líquido do imposto de $10,5 \% \times \mathrm{R} \$ 40.000=\mathrm{R} \$ 4.200$;

ii Custaram, líquido do imposto, $7 \% \times \mathrm{R} \$ 40.000=(\mathrm{R} \$ 2.800)$;

iii Logo, os acionistas ganharam, adicionalmente, $\mathrm{R} \$ 1.400$ de lucro líquido. Que, somados aos $\mathrm{R} \$ 6.300$ produzidos pelo seu próprio capital, deram o lucro líquido total de $\mathrm{R} \$ 7.700$;

iv Ora, se a empresa ganha, por causa da dívida, $\mathrm{R} \$ 1.400$ a mais por ano, descontando isso pelo custo do capital próprio de $10,5 \%$ na perpetuidade, significa um ganho de $\mathrm{R} \$ 1.400 / 10,5 \%=\mathrm{R} \$ 13.333$;

v E eis aí o Goodwill produzido pelo Passivo da empresa.

Ainda, uma diferente forma de comprovação: o ganho no Passivo, ou seu Goodwill, ou seja, o que é acrescido de valor ao Valor Econômico do Patrimônio Líquido, é a diferença entre a) o serviço total da dívida descontado pelo custo líquido dessa dívida e b) esse mesmo serviço total descontado pelo custo do capital próprio caso, o único serviço da dívida é a despesa financeira paga anualmente, líquida dos tributos. Tem-se, chamando DFL à Despesa Financeira Líquida dos Tributos e $k d L$ ao custo do Passivo líquido do tributo:

$$
\begin{aligned}
& \text { Goodwill do Passivo }\left(G_{P}\right)=\text { Ganho na Dívida }=\frac{D F L}{k d L}-\frac{D F L}{k e} \\
& G_{P}=\frac{R \$ 2,800}{10 \% \times(1-30 \%)}-\frac{R \$ 2,800}{10.5 \%}=R \$ 40,000-R \$ 26,667=R \$ 13,333
\end{aligned}
$$




\section{Goodwill do Ativo concomitante com o Goodwill do Passivo e algumas Confusões}

O verdadeiro Valor Econômico de um Ativo é o valor presente do fluxo de caixa líquido que ele produz, trazido a valor presente por taxa de desconto que considera o fator tempo e o risco exclusivo desse mesmo Ativo. Introduzir no Valor do Ativo o efeito de parte dele ser financiada com custo diferente do custo do capital próprio significa dizer que o automóvel vale mais ou menos, por si só, dependendo da forma com que foi financiado. Se um automóvel vale, à vista, $\mathrm{R} \$ \mathrm{X}$, e se tem no mercado um valor superior a esse porque está financiado a uma taxa totalmente subsidiada, e a dívida é transferível ao novo adquirente, há que se considerar que o valor da transação não é o relativo apenas ao veículo, mas, sim, à conjugação do veículo e da sua dívida. E é preciso separar um e outro. É isso que não se tem feito nas avaliações de empresas de forma geral e também não se pratica na contabilidade: quanto vale o Ativo e quanto vale o Passivo, em termos econômicos, à base do valor presente dos seus reflexos no caixa da empresa, e a determinação da eventual existência de Goodwill no Ativo ou no Passivo ou em ambos.

No tópico anterior, apenas admitimos que a taxa de retorno líquido do Ativo é igual ao ke para isolar o Goodwill no Passivo. Mas, se o Ativo produzir mais do que o ke, ele também gerará Goodwill. Refaçamos os cálculos da mesma simulação anterior, mas admitindo que a taxa de retorno bruta $x$ do Ativo seja de $18 \%$, e não 15\%, basta refazer o cálculo e ter-se-á que o Lucro Operacional Líquido, igual ao Fluxo de Caixa Operacional Líquido, será então de $\mathrm{R} \$ 12.600$ e não mais $\mathrm{R} \$ 10.500$. O Lucro Líquido será de R\$9.800, e o Valor Econômico do Patrimônio Líquido da Empresa será de R\$93.333 (R\$9.800/10,5\%), gerando o Goodwill de R $\$ 33.333$, e não R $\$ 13.333$.

E é visível que esse Goodwill agora foi acrescido porque, se o Ativo produz $\mathrm{R} \$ 12.600$, ele vale $\mathrm{R} \$ 120.000$ em "termos econômicos" e, não, R\$100.000. Eis aí o Goodwill genuinamente do Ativo de uma ou várias unidades geradoras de caixa dele.

Assim, se alguém pagar R $\$ 93.333$ por todo o Patrimônio Líquido que, em “termos contábeis" e de Valores Justos de seus Ativos e Passivos, é de $\mathrm{R} \$ 60.000$, paga um ágio por expectativa de rentabilidade futura derivado de duas fontes. A conta de Investimento no balanço da investidora deveria apresentar:

Equivalência Patrimonial da Controlada

Goodwill gerado pelo Ativo da Controlada

Goodwill gerado pelo Passivo da Controlada

Investimento total
$\mathrm{R} \$ 60.000$

$\mathrm{R} \$ 20.000$

$\underline{\mathrm{R} \$ 13.333}$

$\mathrm{R} \$ 93.333$

Se, diferentemente da hipótese simplificada de perpetuidade aqui admitida, tivéssemos a realidade da vida, visivelmente o Goodwill do Ativo teria um comportamento, e o do Passivo, outro. Se o Passivo fosse sendo liquidado ao longo do tempo, por exemplo, esse Goodwill seria menor, relativo apenas ao tempo de existência de uma captação de recursos que custa menos do que o Ativo onde está aplicado produz, e teria que ir sendo "amortizado" paulatinamente, mesmo que via impairment, já que seu valor iria diminuindo ao longo do tempo.

O interessante é notar que pode haver o caso, e isso não é absolutamente nada difícil de encontrar na prática brasileira, de empresa que tenha, no Ativo, um genuíno "Badwill", pela incapacidade desse Ativo produzir retorno líquido compatível com o custo do capital próprio, mas que tenha uma Dívida tão subsidiada que faça com que seu Patrimônio Líquido tenha um Valor Econômico onde aparece Goodwill. Nas regras contábeis atuais, esse Goodwill será alocado a uma unidade geradora de caixa do Ativo da adquirida (sic); que loucura! Na verdade, ele é derivado do Passivo e é, no Passivo, maior do que o considerado na negociação, que a empresa, obviamente compensará o quanto ela na verdade tem de perda no Ativo. E será que alguém não iria fazer o impairment do Ativo que não produz retorno condizente? Talvez não por outro enorme equívoco. 


\subsection{O uso do WACC e do Fluxo de Caixa da Empresa}

Poderia ser perguntado: mas o Ativo não é comumente avaliado pelo fluxo de caixa que ele produz descontado pelo Custo Médio Ponderado de Capital? Afinal, o tradicional e mais utilizado método de avaliação de empresas não financeiras é o baseado no Fluxo de Caixa da Empresa (ou da Firma) e, não, no Fluxo de Caixa dos Acionistas. Até o presente momento nesse trabalho só utilizamos este último, avaliando a empresa pelo que ela como um todo produz descontando pelo custo do capital próprio, e também avaliamos o Ativo também com o desconto pelo custo do capital próprio.

Mas o modelo do Fluxo de Caixa da Empresa faz diferente, utilizando-se do WACC (Custo Médio Ponderado do Capital), média entre o custo do capital de terceiros e o próprio. Ocorre que é comum na prática e em algumas literaturas ver-se o enorme erro de calcular o WACC com base nos valores "contábeis" de Passivo e Patrimônio Líquido. Desde a origem desse conceito, Prêmios Nobel Modigliani e Miller, década de 50, isso é inverdade. O WACC só pode ser calculado com base no Valor Justo do Passivo (valor de mercado, conforme expressão da época) e no Valor Econômico do Patrimônio Líquido (nunca com base em seu valor contábil). Daí o processo circular: precisa-se do Valor Econômico do Patrimônio Líquido para cálculo do a ser utilizado no cálculo do Valor Econômico do Patrimônio Líquido (?).

Muito rapidamente, e sugerindo a tese de doutoramento de Martins (2005) já mencionada e o artigo de Martins e Martins (2015) também citado para mais detalhes, veja-se como ficaria o cálculo, conforme esse modelo do Fluxo de Caixa da Empresa aplicado erroneamente, e utilizemos os dados da segunda simulação, com o Ativo realmente produzindo mais do que o capital próprio.

O cálculo do WACC, errôneo, com fundamento nos valores "contábeis" de Passivo e Patrimônio Líquido seria dado por:

$$
\begin{aligned}
& \text { WACC falso }=\frac{k d \times P}{(P+P L)}+\frac{k e \times P L}{(P+P L)} \\
& \text { WACC falso }=7 \% \times 40 \%+10,5 \% \times 60 \%=9,1 \%
\end{aligned}
$$

Valor Econômico da Empresa, $V_{E}$, (como se estivesse avaliando o Valor do Ativo):

$$
V_{E} \text { falso }=\frac{L o}{\text { WACC falso }}=\frac{R \$ 12.600}{9,1 \%}=\mathrm{R} \$ 138.462
$$

$V_{\text {E }}$ falso

$(-)$ Valor do Passivo $(P)$

$V_{P L}$ falso $=$
$\mathrm{R} \$ 138.462$

(R\$ 40.000)

$\mathrm{R} \$ 98.462$

Ou seja, o Valor do Patrimônio Líquido, que calculamos antes em R $\$ 93.333$, seria assim apurado em $\mathrm{R} \$ 98.462$. Invista isso e veja se consegue ganhar os $10,5 \%$ que foram definidos como o custo do capital próprio. Isso gera a necessidade de um Lucro Líquido de $\mathrm{R} \$ 10.339$, mas ele só chega a $\mathrm{R} \$ 9.800$., ou seja, o valor assim calculado está errado.

Se se recalcular essa fórmula com base no valor do WACC verdadeiro, calculado com o Patrimônio Líquido pelo seu Valor Econômico de R\$93.333, tem-se:

$$
\text { WACC verdadeiro }=\frac{k d \times P}{\left(P+V_{P L}\right)}+\frac{k e \times V_{P L}}{\left(P+V_{P L}\right)}=9,45 \%
$$


WACC verdadeiro

9,45\%

$V_{E}$ verdadeiro $(\mathrm{R} \$ 12.600 / 9,45 \%)$

$(-)$ Valor do Passivo $(P)$

$V_{P L}$ verdadeiro $=$
$\mathrm{R} \$ 133.333$

$(\underline{\mathrm{R} \$ 40.000})$

$\mathrm{R} \$ 93.333$

\subsection{Um Modelo mais Completo}

Essa última descrição do Valor Econômico do Patrimônio Líquido no final do item anterior tem, também, um problema: ele estabelece que o valor da Empresa como um todo, antes da dívida, é $\mathrm{R} \$ 133.333$. Mas isso esconde que esse número é composto de duas parcelas: o genuíno valor do Ativo, individualizado, de $\mathrm{R} \$ 120.000$, e o Goodwill do Passivo, nosso agora já velho amigo, de R $\$ 13.333$. Assim, a tese mencionada sugere, com algumas adaptações:

Valor Justo do Ativo $(A)$

Goodwill do Ativo = Valor Econômico do Ativo - Valor Justo do Ativo

$G_{A}=V_{A}-A=\frac{L o}{k e}-A=\frac{R \$ 12.600}{10,5 \%}-\mathrm{R} \$ 100.000$

Ganho na Dívida $=$ Goodwill do Passivo $=\frac{D F L}{k d L}-\frac{D F L}{k e}$
Valor Econômico da Empresa

$(-)$ Valor Justo do Passivo $(P)$

Valor Econômico do Patrimônio Líquido $\left(V_{P L}\right)$
$=\mathrm{R} \$ 100.000$

$=\mathrm{R} \$ 20.000$

$=\mathrm{R} \$ 13.333$

$=\mathrm{R} \$ 133.333$

$=(\underline{\mathrm{R} \$ 40.000})$

$=\mathrm{R} \$ 93.333$

\subsection{Considerações Adicionais}

Há muitos pontos a discutir, mas chamamos a atenção para alguns, principalmente, para o caso da afirmação feita nesse trabalho de que o Valor Econômico do Ativo deve ser calculado com a taxa de desconto representada pelo $k e$. Isso é genuinamente verdadeiro para o caso de o Patrimônio Líquido ser o único financiador do Ativo. Mas, quando há uma primeira dívida tomada, é de se esperar que se, por um lado, há, normalmente, um Ganho na Dívida, há, por outro lado, um acréscimo no ke por conta do acréscimo de risco dos acionistas.

Assim, há que se calcular o Valor Econômico do Ativo com base no ke da empresa desalavancada, e se terão aí dois componentes: perda de valor do Patrimônio Líquido por conta do acréscimo do ke, e Ganho na Dívida, esperando-se que este seja maior do que aquele (Modigliani e Miller (1958) afirmavam que, em teoria, deveriam se equivaler, a menos dos efeitos fiscais do custo da dívida, mas não se vai aqui entrar nesse mérito).

Na verdade, haveria sempre 'cascatas' de Perda de valor do Patrimônio Líquido a cada trancha de novo Passivo e também variação no Ganho da Dívida.

Outro ponto: há que se considerar a figura fiscal do Juro Sobre Capital Próprio, que produz modificações no ke por sua interferência tributária e, consequentemente, no Valor Econômico do Ativo e do Patrimônio Líquido (não esquecer que a empresa paga menos imposto, mas o acionista é tributado sobre esse "Juro", e o cálculo precisa abranger ambos).

Mais um: a conta de Fornecedores deveria sempre ser entendida como um Passivo Oneroso e tratada a valor presente e com os juros computados na despesa financeira e, não, no custo da mercadoria vendida. Todavia, nem sempre isso é aplicado contabilmente, ou as taxas de desconto não são devidamente descritas a ponto de produzir um grau razoável de aceitação. Por isso, costuma-se tratar essa conta como parte dos Passivos Não Onerosos, o que obviamente produz algumas distorções.

Mas vamos parar com essas considerações adicionais, mesmo sabendo que outras há. 


\section{Um Caso Real Brasileiro}

É visível que, na normalidade, sendo as dívidas tomadas a um custo líquido do imposto de renda (obviamente aqui entendendo a soma desse imposto com a contribuição social sobre o lucro líquido) inferior ao retorno do Ativo, todas as empresas nessas condições têm Goodwill derivado de seu Passivo.

Claro que, no nosso País, algumas vezes as taxas de juros têm exorbitado as taxas de retorno dos Ativos onde esses Passivos são aplicados, destruindo o Valor Econômico do Patrimônio Líquido.

Por outro lado, as generosas taxas de juros cobradas principalmente pelo BNDES e algumas agências estatais fomentadoras do desenvolvimento (e de privilégios abusivos, às vezes) têm feito proliferar Valores Econômicos de Patrimônios Líquidos fundamentados, em grande parte, e às vezes na sua integralidade, no Goodwill desses Passivos.

E vimos como é fácil se computar esse Goodwill que nada tem a ver com qualquer unidade geradora de caixa. Basta estarem acessíveis o Passivo, seu custo financeiro, seu perfil ao longo do tempo (para não se admitir a exageradamente simplificada ideia da perpetuidade) e o custo do capital próprio. É lógico que este último é o mais complicado de todos, já que volúvel, subjetivo, determinado pelos sócios (e cada um com o seu próprio $k e$ ), mas existem diversas fontes que procuram se aproximar desse custo do capital próprio com razoável sucesso na aproximação (espera-se, pelo menos).

Assim, podemos nos arriscar a um exemplo real, sem qualquer preocupação com exatidão meticulosa, mas muito mais para mostrar o potencial dessa análise.

Vejamos o caso da Vale, que em suas demonstrações contábeis de 2016, evidencia, média simples do ano, em milhões de reais:

Passivo Financeiro $(P)$

Patrimônio Líquido $(P L)$

Ativo Total menos o Passivo Não Financeiro $(A)$
$\mathrm{R} \$ 104.115$

$\underline{\mathrm{R} \$ 136.561}$

$\mathrm{R} \$ 240.676$

Esse Passivo, conforme as notas explicativas da empresa e a demonstração do resultado, e excluindo variações por inflação e por moeda estrangeira (exagero de simplificação sim, mas aqui isso é deliberado - estamos trabalhando com taxas reais, isentas dos efeitos da inflação, e admitindo variação cambial igual à inflação para evitar outros desvios e ajustes), esteve sujeito, durante 2016, à taxa média de encargo financeiro real anual, líquida já da assumida alíquota de $34 \%$ de tributos sobre o lucro, de $3,90 \%$, produzindo a despesa financeira de $\mathrm{R} \$ 4.060$ milhões ( $\mathrm{R} \$ 6.152$ antes dos tributos). $\mathrm{O} k e$, estimado pelo Centro de Estudos do Mercado de Capitais (Cemec), em termos reais (tomando-se o IPCA como deflator), foi de 7,88\% a.a.

Se essa dívida fosse perpétua, ou se a empresa fosse capaz de substituí-la eternamente por outras de mesmo perfil em termos de encargo, o valor econômico dessa dívida seria de $\mathrm{R} \$ 51.523$ milhões, com o Goodwill do Passivo de R $\$ 52.592$ milhões.

Como a empresa apresenta em suas demonstrações contábeis o perfil de vencimento dessas dívidas, se se partir da hipótese de que a empresa iria pagando-as todas nos seus vencimentos e não as fosse renovando, e mantendo a mesma taxa de juros (jamais uma administração faria isso se conseguisse essas taxas!), assim mesmo o Goodwill do Passivo seria de $\mathrm{R} \$ 17.905$ milhões.

Para se ter uma ideia do quanto é significativo esse valor, em 31/12/2016 o valor de mercado da Vale era de $\mathrm{R} \$ 127.734$ milhões, ou seja, a partir desses dados, tem-se que o maior componente individual do Goodwill da Vale parece estar concentrado no seu Passivo e, não, no seu Ativo! 


\section{Conclusões}

Neste trabalho, de maneira simplificada e didática, expusemos essa figura aparentemente desconsiderada quase que por completo no mundo acadêmico, totalmente desconsiderada no mundo normativo contábil, mas presente na cabeça dos investidores e analistas mais avisados, que é a figura do Goodwill, que deriva do Passivo de uma empresa e, não, de seus Ativos tangíveis e intangíveis.

Revisitamos a parca bibliografia a respeito e salientamos o modelo brasileiro desenvolvido pelo Prof. Vinícius Aversari Martins, criado para um dimensionamento relativamente rápido desse Goodwill, modelo esse que separa o Goodwill total de uma empresa em seus dois componentes: a) quanto é formado pela capacidade dos Ativos de gerar lucros anormais, e b) quanto é formado por se ter Passivo de financiamento com taxa de encargo líquido de tributos inferior ao custo do capital próprio. Mostramos também que esse modelo produz uma mensuração muito mais adequada do Valor da Firma de uma empresa, o que não pode ser conseguido pelo uso do WACC tradicional.

Pode-se concluir, pela importância do assunto, pela pouquíssima bibliografia, pela pobreza do tratamento do assunto em termos de ensino e pesquisa contábeis e pela total ausência desse conceito na normatização contábil internacional, que muito há a investigar, desenvolver, ensinar e normatizar sobre a matéria. Urge uma mudança nos dois campos, o acadêmico e o da normatização. Mas, apesar de essa matéria ser melhor conhecida no mundo prático, urge também um desenvolvimento mais apropriado e mais transparente sobre a ideia e o cálculo desse Goodwill do Passivo.

\section{Referências}

Cheng, M. C. \& Tzeng, Z. C. (2011). The effect of leverage on firm value and how the firm financial quality influence on this effect. World Journal of Management, 3(2), pp.30-53.

Choi, J. J. (1988). Debt financing and the cost of capital in the neoclassical investment model. The American Economist, 32(1), pp. 19-23.

Comitê de Pronunciamentos Contábeis. (2010). Pronunciamento Técnico CPC 01 (R1) - Redução ao Valor Recuperável de Ativos. Recuperado de http://www.cpc.org.br/Arquivos/Documentos/27_ CPC_01_R1_revisão08.pdf

Comitê de Pronunciamentos Contábeis. (2010). Pronunciamento Técnico CPC 04 (R1) - Ativo Intangível. Recuperado de http://www.cpc.org.br/Arquivos/Documentos/187_CPC_04_R1_rev\%2008.pdf

Comitê de Pronunciamentos Contábeis. (2011). Pronunciamento Técnico CPC 15 (R1) - Combinação de Negócios. Recuperado de http://www.cpc.org.br/Arquivos/Documentos/235_CPC15R1_rev_06.pdf

Edwards, E. \& Bell, P. (1961). The theory and measurement of business income. California: University of California Press.

Kane, A., Marcus, A. J. \& McDonald, R. L. (1985). Debt policy and the rate of return premium to leverage. Journal of Financial and Quantitative Analysis, 20(4), pp. 479-499.

Leão, L. G. \& Vasconcelos, R. A. (2010). Depósitos estáveis em cooperativas de crédito: um Ativo intangível na forma de Goodwill não adquirido. Gestão Contemporânea, 6(6), pp. 227- 254.

Martins, E. \& Martins, V. A. (2015). Contabilidade e finanças: a temerária utilização do WACC. Revista Universo Contábil, 11(1), pp. 25-46.

Martins, V. A. (2002). Contribuição à avaliação do Goodwill: depósitos estáveis, um Ativo intangível. Dissertação de mestrado, Universidade de São Paulo, São Paulo, SP, Brasil

Martins, V. A. (2005). Interações entre estrutura de capital, valor da empresa e valor dos Ativos. Tese de doutorado, Universidade de São Paulo, São Paulo, SP, Brasil. 
Martins, V. A., Carvalho, L. N. \& Assaf Neto, A. (2008). Anatomia do valor de empresas. RAC-Revista de Administração Contemporânea, 12(4), pp. 1071-1105.

Modigliani, F. \& Miller, M. H. (1958). The cost of capital, corporation finance and the theory of investment. American Economic Review, 48(3), pp. 261-297. 